\title{
Laparotomy Myomectomy: Epidemiology, Indications and Prognosis at Loandjili General Hospital (Republic of Congo)
}

\author{
Eouani Levy Max Emery ${ }^{1,3,}$, , Mokoko Jules Cesar ${ }^{2,3}$, Buambo Gauthier Regis Jostin ${ }^{2}$, \\ Potokoue Mpia Sekangue Samantha Nuely ${ }^{2,3}$, Itoua Clautaire ${ }^{2,3}$, Iloki Leon Herve ${ }^{2,3}$ \\ ${ }^{1}$ Obstetrics and Gynecology Department, Loandjili General Hospital, Pointe Noire, Congo \\ ${ }^{2}$ Obstetrics and Gynecology Department, Brazzaville University Hospital, Brazzaville, Congo \\ ${ }^{3}$ Faculty of Health Sciences, Marien Ngouabi University, Brazzaville, Congo \\ Email address: \\ eouani@yahoo.fr (E. L. M. Emery),jlsmokoko@gmail.com (M. J. Cesar), buambogauthier@yahoo.fr (B. G. R. Jostin), \\ samanthasekangue@gmail.com (P. M. S. S. Nuely), clautairei@yahoo.com (I. Clautaire), herviloki@yahoo.fr (I. L. Herve) \\ ${ }^{*}$ Corresponding author
}

\section{To cite this article:}

Eouani Levy Max Emery, Mokoko Jules Cesar, Buambo Gauthier Regis Jostin, Potokoue Mpia Sekangue Samantha Nuely, Itoua Clautaire, Iloki Leon Herve. Laparotomy Myomectomy: Epidemiology, Indications and Prognosis at Loandjili General Hospital (Republic of Congo). Journal of Gynecology and Obstetrics. Vol. 7, No. 5, 2019, pp. 145-148. doi: 10.11648/j.jgo.20190705.15

Received: August 15, 2019; Accepted: September 18, 2019; Published: October 9, 2019

\begin{abstract}
To describe the epidemiological profile of patients, list myomectomy indications and report their prognosis at Loandjili General Hospital. A descriptive cross-sectional study conducted from 1 January 2016 to 31 December 2018 in the Gynecology Department of Loandjili General Hospital, including exhaustively all patients operated for myomectomy. The variables studied were pre (age, gestity, parity, indication), per (myoma measures, blood loss, intraoperative transfusion, complications and peroperative incidents) and postoperatively (hospital stay). Ninety-two patients had been received for surgical management of uterine fibroids out of a total of 1,455 gynecological procedures or $6.3 \%$. The median age was 36.5 years [range 27 - 44] with a peak in the 36 to 40 age group (37\%). The median gestity and parity were respectively 2 [range 0 - 12] and 1 [range 0 - 7]. More than half of the patients were nulliparous (51.1\%). In 71.7\% of cases $(n=66)$, myomectomy was performed in a context of desire for maternity. Indications for myomectomy were hemorrhage (46.7\%), large uterus above the umbilicus $(37 \%)$ and pelvic pain $(16.3 \%)$. The polymyomectomy was performed in $64.1 \%$ of the cases $(n=59)$ with nuclei of size varying between 2 and $20 \mathrm{~cm}$. The morbidity was marked on the one hand by anemia $(\mathrm{n}=14$ or $14 \%)$ secondary to an intraoperative haemorrhage which resulted in two cases in performing a hemostatic hysterectomy and in the other by rupture of the uterine cavity. Postoperative blood loss was estimated at 200 to $1400 \mathrm{ml}$, resulting in more than half of the patients receiving blood transfusions (58\%). Myomectomy by laparotomy is often accompanied by significant blood spoliation thus increasing the postoperative morbidity. Techniques that minimize intraoperative blood loss should be used for laparotomy myomectomy.
\end{abstract}

Keywords: Myomectomy, Laparotomy, Epidemiology, Indications, Prognosis, Pointe Noire

\section{Introduction}

Uterine fibroids are common benign tumours in women of childbearing age. They affect between 25 and $40 \%$ of women during periods of genital activity [1, 2]. Myomectomy tends to be invasive and expensive; its benefit is to improve the quality of patients' lives and is more in demand in women who want to keep their uterus [3] Myomectomy is an intervention of choice as well as in young patients as well as those with a desire for motherhood. Several therapeutic options are now listed. In our context, in few are available, so myomectomy by laparotomy is the princess intervention for this indication in our daily practice. This is how we undertook this study to describe the epidemiological profile of patients, list myomectomy indications and report their prognosis at Loandjili General Hospital. 


\section{Methods}

This was a descriptive cross-sectional study conducted from 1 January 2016 to 31 December 2018 in the Obstetrics and Gynecology Department of Loandjili General Hospital, including exhaustively all patients undergoing laparotomy myomectomy.

The preoperative assessment was based on clinical evaluation, pelvic ultrasound and endovaginal ultrasound (sometimes completed with hysterosonography in case of suspicion of submucosal myoma), hysterosalpingography and spermogram of the spouse (in case of desire to maternity manifested or later) and cervival-uterine smear.

Laparotomy was done under general anesthesia or spinal anesthesia, depending on the case. No prior hemostasis technique described in the literature was preferentially performed before myomectomy. In the case of bulky polymyomatous uterus, a tourniquet was used with a latex glove tied at the level of the uterine isthmus to reduce intraoperative blood loss.

The variables studied were preoperative (age, severity, parity, uterine size, type of myoma according to FIGO classification, indication of myomectomy), intraoperative (number and size of myomas, blood loss, intraoperative complications) and postoperatively (transfusion blood, hospital stay).

The Epi-info 7 software was used for data analysis. The qualitative and quantitative variables were respectively represented as proportions and medians.

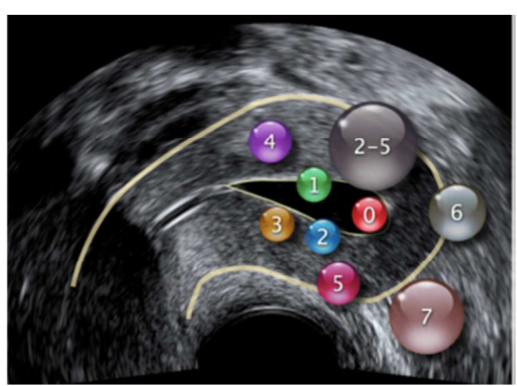

Figure 1. Classification of myomas (FIGO 2011) [4]

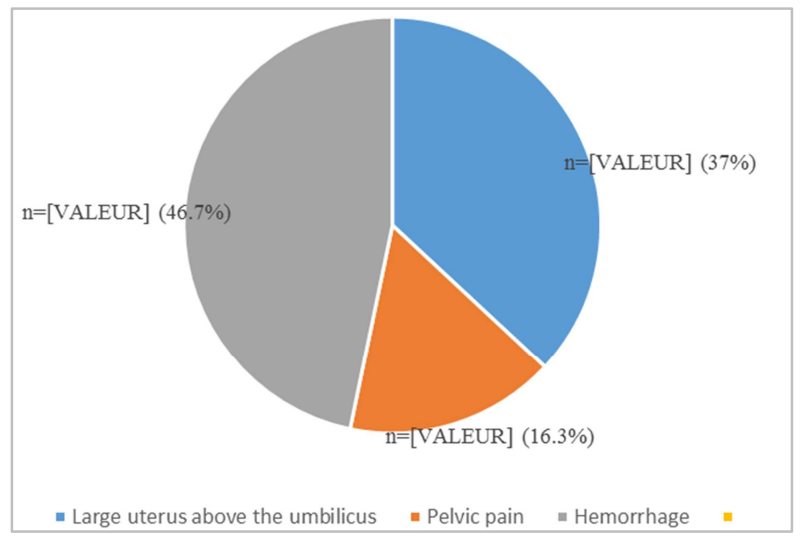

Figure 2. Indication of myomectomy. The polymyomectomy was performed in $64.1 \%$ of the cases $(n=59)$ with nuclei of size varying between 2 and $20 \mathrm{~cm}$. Intraoperative, the gestures associated with myomectomy were ovarian drilling $(n=13$ or $14 \%)$ and adhesyolis $(n=6$ or $7 \%)$.

\section{Results}

Ninety-two patients were received for surgical management of uterine fibroids out of a total of 1455 gynecological procedures or $6.3 \%$.

The median age was 36.5 years [range 27 - 44]. The most represented age groups were between 36 and 40 years (37\%), followed by those between 24 and 30 years (26\%), those between 31 and 35 years $(23 \%)$ and that between 41 and 44 years $(13 \%)$. Reproductive characteristics were reported in Table 1 .

Table 1. Reproductive Characteristics.

\begin{tabular}{lll}
\hline & $\mathbf{N}$ & $\mathbf{\%}$ \\
\hline Gestity & & \\
0 & 24 & 26.1 \\
1 & 21 & 22.8 \\
$2-3$ & 28 & 30.4 \\
$4-12$ & 19 & 20.7 \\
Parity & & \\
0 & 47 & 51.1 \\
1 & 26 & 28.3 \\
$2-3$ & 14 & 15.2 \\
$4-7$ & 5 & 5.4 \\
Total & 92 & 100 \\
\hline
\end{tabular}

The median gestity and parity were respectively 2 [range 0 12] and 1 [range 0 - 7]. More than half of the patients were nulliparous. The myomas to be operated were types 1 to 7 of FIGO (Figure 1) and associated in most cases.

The uterus had a median size of $18.5 \mathrm{~cm}$ [range $12-25$ ].

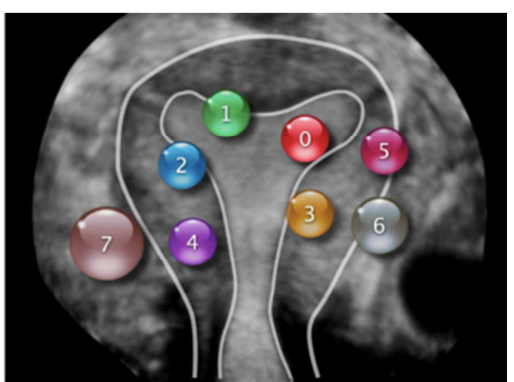

Myomectomy indications were shown in Figure 2. In 71.7\% of cases $(n=66)$, myomectomy was performed in a context of desire for maternity.

The morbidity was marked on the one hand by anemia $(\mathrm{n}=$ 14 or $14 \%$ ) secondary to an intraoperative haemorrhage which resulted in two cases in performing a hemostatic hysterectomy and in the other by rupture of the uterine cavity.

Postoperative blood losses were estimated at 200 to 1400 $\mathrm{ml}$. More than half of the patients were transfused $(\mathrm{n}=53$ or $58 \%)$.

\section{Discussion}

Gynecological surgery plays an important role in the service activity, and myomectomy accounts for $6.3 \%$. Myomectomy is a well-known conservative surgery for myomas, offered for treatment of symptomatic uterine 
fibroids in women who desire to maintain fertility and which can be performed by laparotomy, laparoscopy or hysteroscopy. Although an important option for women who wish to retain their uterus or enhance their fertility, myomectomy would expose patients to additional interventions [5].

The context of countries with modest human and material resources (absence or insufficiency of a qualified surgical team, no laparoscopy or hysteroscopy), such as ours, contributes, on the one hand, to the exclusive choice of laparotomy. On the other hand, the choice of laparotomy as the first route, would be oriented by the profile of the patients. In fact, the management of women with uterine myoma should be personalized according to the symptomatology, the size and location of the fibroids, the age of the patient, and her needs and wishes for the preservation of the uterine myoma. fertility or uterus, the availability of treatment and the therapist's experience $[5,6]$. This is how the patients of this series were young adults of median age less than 40 years, nulliparous and primiparous in more than two-thirds of the cases and most of them presenting a large uterus measuring $15 \mathrm{~cm}$ long axis. This profile is an African reality supporting the hypothesis of a variation in the incidence of myomas by ethnicity with high numbers in a predominantly black population [4].

Also, the often-late diagnosis of complicated myomas during periods of subfertility, in a population led to procreation, contributes to the choice of a conservative surgery. Otherwise, Ahdad-Yata in France, reports that myomas are found in 5 to $10 \%$ of infertile patients and are however considered as the only factor of infertility in 1 to $3 \%$ of cases [4]. In this context, Canadian gynecologists recommend that women who struggle with infertility should be deployed for evaluation and classification fibroids (especially with regard to those which exert effects on the endometrial cavity) are adequately conducted using transvaginal ultrasound, of hysteroscopy, hysterosonography or imaging by magnetic resonance [7].

Although laparotomy was the exclusive surgical approach, it would not be detrimental to the obstetrical future of patients wanting maternity. This is especially true since Fukuda in his series found no significant difference between myomectomies by laparotomy and laparotomy, both in terms of vital prognosis (hemodynamic status) and functional prognosis (subsequent fertility) [8]. The impact of myomectomy on fertility depends on the location of the myoma. In fact, myomas type 6 and 7 have little influence on fertility and myomectomy is not indicated in these situations [4]. For myomas type 3 to 5 , the association with infertility is demonstrated without the myomectomy having proven effective for myomas less than $5 \mathrm{~cm}$. On the other hand, for type 0,1 and 2 (submucosal) myomas, hysteroscopic myomectomy seems to be beneficial for fertility [4]. According to the French recommendations of 2011, a complete hysteroscopic resection of even asymptomatic submucous myomas is recommended in patients with a desire for pregnancy [9]. Also, the surgical approach would only impact the fragility of the uterine muscle in the event of rupture of the uterine cavity, resulting in a prophylactic caesarean section during subsequent deliveries. [10]. However, the absence of an alternative to laparotomy in our resource-poor setting would increase its impact on subsequent fertility especially in cases of endocavitary localization.

In the context of laparotomy, such as ours, because of the size and number of myomas, myomectomy is most often associated with a high rate of perioperative blood transfusions due to intraoperative hemorrhage $[11,12]$. Given the elevated risk of transfusion for this procedure and the potential serious adverse consequences of transfusion, medical interventions to reduce blood loss during myomectomy have the potential to prevent transfusion and its associated risks.

Numerous methods of hemostasis to reduce intraoperative blood loss during myomectomy have been reported, including both medications (ergometrine, oxytocin, misoprostol, sulprostone, aprotinin, aminocaproic, acid, recombinant factor VIIa, gelatin-thrombin hemostatic sealant and tranexamic acid) than vascular ligations (uterine arteries, hypogastric arteries, isthmic tourniquet) [4-11].

\section{Conclusion}

Myomectomy by laparotomy is widely practiced in our hospitals for reasons of insufficient technical platform and myoma-related characteristics. It is the treatment of choice for women with symptomatic myomatous uteri who want to maintain their uterus and enhance their fertility. The absence of an alternative to laparotomy in our context of resource-poor countries would increase its impact on subsequent fertility and would need to be evaluated. In addition, it is often accompanied by significant blood depletion, thereby increasing postoperative morbidity and requiring the use of techniques that minimize intraoperative blood loss.

\section{Conflicts of Interest}

All the authors do not have any possible conflicts of interest.

\section{References}

[1] Villot A, Cheret-Benoist A, Creveuil C, Turck M, Dreyfus M, Benoist G. After Myomectomy, Do Patients Have the Right to Deliver Vaginally? Result of the Monocentric Study. Gynecol Obst and Fert. 2015; 43 (7-8) 496-501.

[2] Bendifallah S, Brun JL, Fernandez H. Place of Myomectomy in a Patient in a Situation of Infertility. J Gynecol Obstet Reprod Biol 2011; (40): 885, 901.

[3] Chen I, Lisonkova S, Joseph KS, Williams C, Yong P, Allaire C. Laparoscopic versus Abdominal Myomectomy: Practice Patterns and Health Care Use in British Colombia. JOGC 2014; (7): 817-23.

[4] Ahdad-Yata N, Fernandez H, Nazac A, Lesavre M, Pourcelot AG, Capmas P. Fertility After Hysteroscopic Resection of Submucosal Myoma in Infertile Women. J Gynecol Obstet Biol Reprod 2016; 45 (6): 563-70. 
[5] Vilos GA, Allaire C, Laberge P-Y, Leyland N. Management of Uterine Leiomyomas. SOGC Clinical Guideline. J Obstet Gynaecol Can 2015; 37 (2): 179-81.

[6] Heike W, Bernhard F-F. Myoma. Swiss Medical Forum 2018; 18 (24): 503-8.

[7] Carranza-Mamane B, Havelock J, Hemmings R. Management of Uterine Fibroids in the Presence of Otherwise Unexplained Infertility. SOGC Clinical Guideline. J Obstet Gynaecol Can 2015; 37 (3): 286-8.

[8] Fukuda M, Tanaka T, Kamada M and al. Comparison of the Perinatal Outcomes after Laparoscopic Myomectomy. Gynecol Obstet invest 2013; 76: 203-8

[9] Marret H, Fritel X, Ouldamer L and al. Therapeutic Management of Uterine Fibroid Tumors: Updated French Guidelines. Eur J Obstet Gynecol Reprod Biol 2012; 165: 156-64.

[10] Véibel HS, Jarcevie R, Gagnon R, Tulandi T. Perspective of Obstetrician on Labor Delivery after Abdominal or Laparoscopic Myomectomy. J Obstet Gynecol Can 2014; 36 (2): 128-38.
[11] Bao J, Simpson AN, Hare GMT, Sholzberg M, Robertson D. Delphi Approach for the Design of an Intraoperative Blood Conservation Pathway for Open Myomectomy. J Obstet Gynaecol Can 2019; S1701-2163 (19) 30531-6.

[12] Fusca L, Perelman I, Fergusson D, Boutet M, Chen I. The Effectiveness of Tranexamic Acid at Reducing Blood Loss and Transfusion Requirement for Women Undergoing Myomectomy: A Systematic Review and Meta-analysis. J Obstet Gynaecol Can 2019; 41 (8): 1185-92.

[13] Fanny M, Fomba M, Aka E and al. Prevention of Bleeding During Laparotomic Myomectomy in Sub-Saharan Africa: Contribution to the Tourniquet on the Uterine Isthmus. Gynecol Obstet Fertil Senol 2018; 46 (10-11): 681-5.

[14] Itoua C, Eouani LME, Obara Ngoli Mbongui P, Koko PS, Iloki LH. Abscence of Dressing versus Dressing in Gynaecological and Obstetrical Surgery at the University Hospital of Brazzaville. Open Journal of Obstetrics and Gynecology 2018; (8): 247-52. 